University of Nebraska - Lincoln

DigitalCommons@University of Nebraska - Lincoln

\title{
Integrating estimates of ecosystem services from conservation programs and practices into models for decision makers
}

Ned H. Euliss Jr.

U.S. Geological Survey, ceuliss@usgs.gov

Loren M. Smith

Oklahoma State University - Main Campus

Shuguang Liu

U.S. Geological Survey

Walter G. Duffy

U.S. Geological Survey

Stephen P. Faulkner

U.S. Geological Survey, faulkners@usgs.gov

See next page for additional authors

Follow this and additional works at: https://digitalcommons.unl.edu/usgsnpwrc

Euliss, Ned H. Jr.; Smith, Loren M.; Liu, Shuguang; Duffy, Walter G.; Faulkner, Stephen P.; Gleason, Robert A.; and Eckles, S. Diane, "Integrating estimates of ecosystem services from conservation programs and practices into models for decision makers" (2011). USGS Northern Prairie Wildlife Research Center. 262. https://digitalcommons.unl.edu/usgsnpwrc/262

This Article is brought to you for free and open access by the US Geological Survey at DigitalCommons@University of Nebraska - Lincoln. It has been accepted for inclusion in USGS Northern Prairie Wildlife Research Center by an authorized administrator of DigitalCommons@University of Nebraska - Lincoln. 


\section{Authors}

Ned H. Euliss Jr., Loren M. Smith, Shuguang Liu, Walter G. Duffy, Stephen P. Faulkner, Robert A. Gleason, and S. Diane Eckles 


\title{
Integrating estimates of ecosystem services from conservation programs and practices into models for decision makers
}

\author{
Ned H. Euliss, Jr., ${ }^{1,7}$ Loren M. Smith, ${ }^{2}$ Shuguang Liu, ${ }^{3}$ Walter G. Duffy, ${ }^{4}$ Stephen P. Faulkner,${ }^{5}$ \\ Robert A. Gleason, ${ }^{1}$ and S. Diane Eckles ${ }^{6}$ \\ ${ }^{1}$ U.S. Geological Survey, Northern Prairie Wildife Research Center, 8711 37th Street Southeast, \\ Jamestown, North Dakota 58401 USA \\ ${ }^{2}$ Oklahoma State University, Department of Zoology, Stillwater, Oklahoma 74078 USA \\ ${ }^{3}$ U.S. Geological Survey, Earth Resources Observation and Science, Mundt Federal Building, 47914 252nd Street, \\ Sioux Falls, South Dakota 57198-0001 USA \\ ${ }^{4}$ U.S. Geological Survey, California Cooperative Fisheries Research Unit, Humboldt State University, 1 Harpst Street, \\ Arcata, California 95521 USA \\ ${ }^{5}$ U.S. Geological Survey, National Wetlands Research Center, 700 Cajundome Boulevard, Lafayette, Louisiana 70506 USA \\ ${ }^{6}$ USD A Natural Resources Conservation Service, Resource Inventory and Assessment Division 5601 Sunnyside Avenue, \\ Beltsville, Maryland 20705 USA
}

\begin{abstract}
Most government agencies involved in land management are seeking consistent approaches to evaluate the effects of specific management actions on ecological processes and concurrent changes on ecosystem services. This is especially true within the context of anthropogenic influences, such as land use and climate change. The Conservation Effects Assessment Project-Wetlands National Component (CEAP-Wetlands) was developed by the U.S. Department of Agriculture (USDA) to evaluate effects of conservation practices on ecosystem services including carbon sequestration for climate stability, groundwater recharge, runoff and flood attenuation, water storage, nutrient and contaminant retention, and wildlife habitat. A primary purpose of CEAP-Wetlands is to provide science-based information in an adaptive monitoring framework for use by the USDA to facilitate policy and management decisions, and to document effects of conservation programs and practices to the federal Office of Management and Budget. Herein, we propose a modeling framework to allow estimation of conservation practice and program effects on various ecosystem services at different temporal and spatial scales. This modeling approach provides the broad view needed by decision-makers to avoid unintended negative environmental outcomes, and to communicate to society the positive effects of conservation actions on a broad suite of ecosystem services.
\end{abstract}

Key words: climate change; Conservation Effects Assessment Project (CEAP); ecological forecasting; ecosystem services; land use; modeling; wetlands.

\section{INTRODUCTION}

Ecosystem degradation has led to the implementation of conservation programs on agricultural landscapes throughout the United States. Initially, programs focused on specific deliverables (e.g., soil conservation), but later shifted to target a broad suite of ecosystem services. For example, the Conservation Reserve Program (CRP), administered by the U.S. Department of Agriculture (USDA), was first implemented to conserve topsoil and reduce crop surpluses, but later expanded to include ecosystem services such as wildlife habitat and carbon sequestration. These services were identified by isolated scientific studies, but the overall impact of conservation programs on them was largely anecdotal.

Manuscript received 27 February 2009; revised 15 July 2010; accepted 22 July 2010. Corresponding Editor: J. S. Baron. For reprints of this Special Issue, see footnote 1, p. S1.

${ }^{7}$ E-mail: ceuliss@usgs.gov
The current Administration's "Fiscal Responsibility" strategy (available online) ${ }^{8}$ to improve federal program performance reinforces public policy initiatives over the last two decades that require federal agencies demonstrate the effectiveness and efficiency of their programs. Within the USDA, the Conservation Effects Assessment Project-Wetlands National Component (CEAPWetlands) is supporting, among other activities, four regional assessments to document the effects of conservation practices and programs on the provisioning of ecosystem services provided by wetlands in agricultural landscapes (Fig. 1). Because data being collected through the regional studies span a diversity of ecosystem services, an unprecedented opportunity exists to develop models to evaluate conservation practice and program effects on these services relative to adaptive management and policy objectives.

${ }^{8}\langle$ http://whitehouse.gov/issues/fiscal/ $\rangle$ 


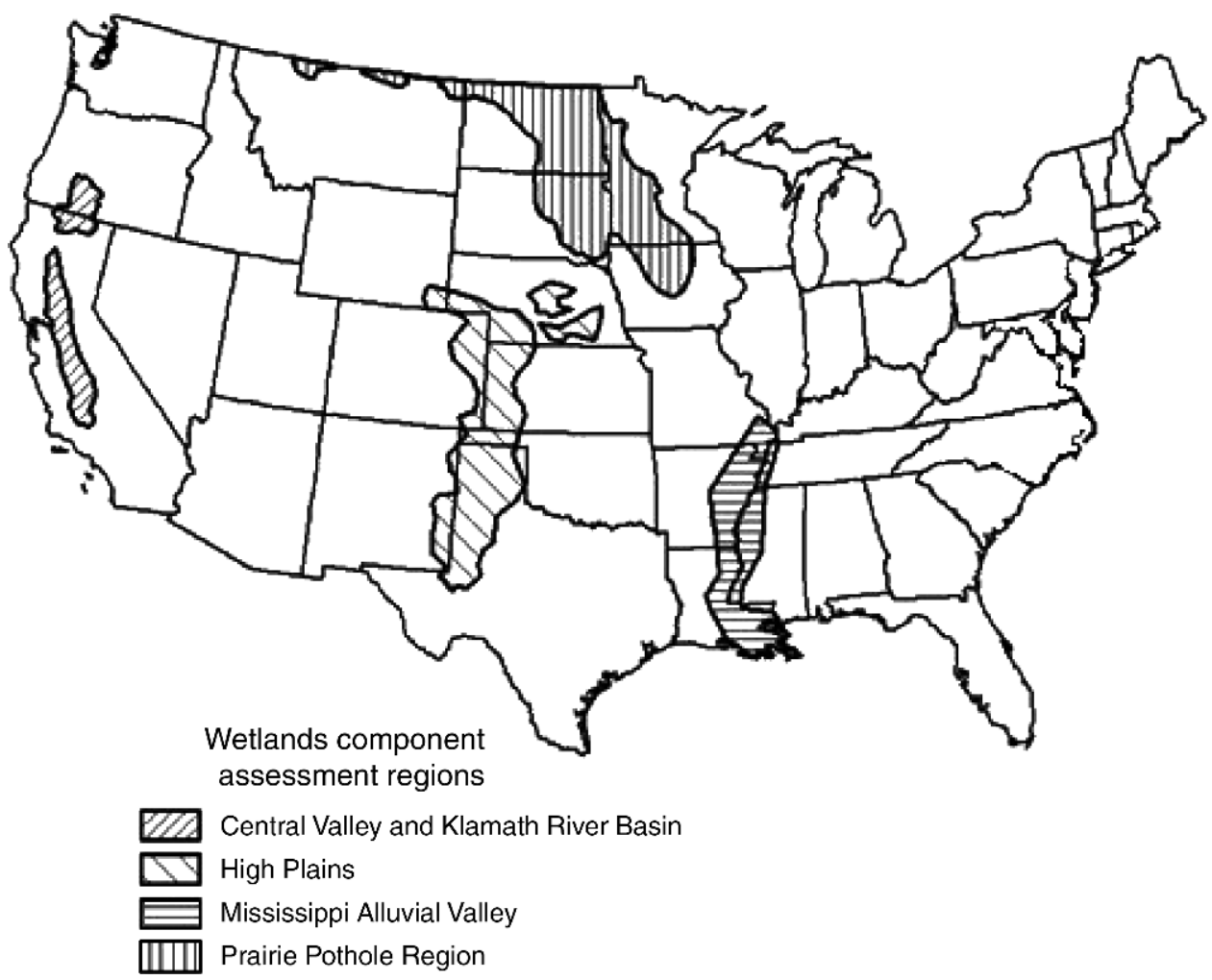

FIg. 1. The location of four of the regional investigations initiated by the Conservation Effects Assessment Project-Wetlands National Component.

While management to ensure ecosystem sustainability is an explicitly stated goal of many government agencies and, in some cases, has become mandated through legislation (Christensen et al. 1996), ecosystem management is daunting because of complex processes involving air, land, water, biota, and humans. Integrating estimates of diverse ecosystem services from assessments, such as CEAP-Wetlands, thus provides an opportunity to shift from the current focus on isolated services or single species to management of ecosystem processes to ensure sustainability of a suite of services. Here, we suggest that data gathered from CEAPWetlands be integrated into development of landscape/ temporal models as forecasting tools for decision makers to predict changes in ecosystem services based on conservation practices and future climate scenarios.

\section{Modeling Approach}

Our basic approach was to develop regionalized ecosystem models that account for dynamic natural drivers of ecosystem processes. The models will be adaptive and sufficiently complex to simultaneously integrate and quantify various ecosystem services. The approach will incorporate multivariate spatial and temporal interactions among ecosystem processes, land use alteration, and climate change. Ecosystem services include groundwater recharge, floodwater storage, sediment and chemical filtration, erosion reduction, water quality improvement, emission reduction of greenhouse gases, carbon sequestration, food and fiber production, fish and wildlife habitat, and biodiversity (Daily 1997). Policy makers and resource managers also need credible estimates of uncertainty associated with model projections to formulate strategies for adaptive management and to identify critical information needs. Such a strategy requires an adaptive modeling system that constantly refines model projections and forecasts by assimilating various near-real-time observations simultaneously in much the same manner as "smart bomb" technology, where a trajectory is modified based on constant-monitoring data on the moving target. Therefore, the objective is to develop a model that assimilates monitoring information constantly such that model projections and regional forecasts become more realistic over time. Moreover, a distributed geospatial modeling system based on open interoperability standards will ensure that complex models can be linked to forecast myriad ecosystem services by users who access models and large data sets through the Internet using portable and stationary computers (Feng et al. 2009).

\section{Frame-based ecosystem model}

The framework required to integrate current estimates of ecosystem services from CEAP-Wetlands into models that forecast outcomes under changing land use and climate scenarios should be based on natural and 


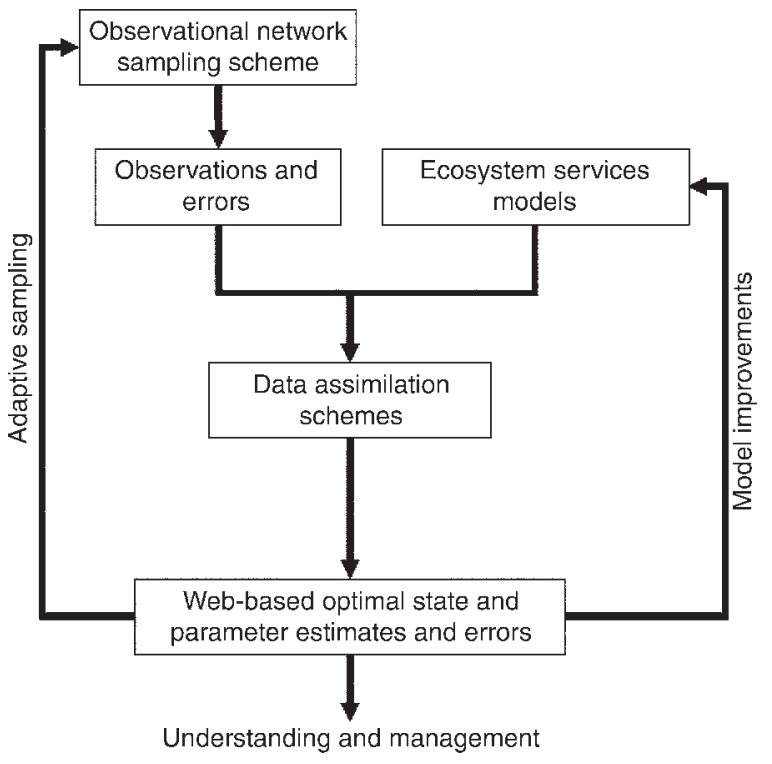

FIG. 2. Conceptual diagram of an integrated and adaptive modeling system that uses data assimilation to continually improve model forecasts.

anthropogenic drivers of ecosystem processes and functions. The frame-based dynamic ecosystem paradigm (Starfield et al. 1993) is an approach well suited to such applications because models can be designed to resemble the structure and function of a particular ecosystem. Using this approach, frames to be modeled are ecosystem states (e.g., successional stages, wetland phases) that are readily identifiable, are of direct management interest, or exert considerable effect on ecosystem services. Frame-based models can be constructed using rules that dictate the transition from one frame to another based on the scientific literature to facilitate critical review of the base model by the scientific community, including ecologists with limited modeling expertise. In some cases, existing models can be used to quantify the specific ecosystem services associated with unique frames. Frame-based models are especially appropriate to forecast change in ecosystem services in geographic areas where temporal variations that determine ecosystem state are highly dynamic. Frame-based models also offer the advantage of being able to expand to include larger spatial areas by extending the paradigm to a patchwork of interacting geographic regions (Starfield et al. 1993).

Frame-based models can thus facilitate the adaptive management and policy goals of conservation agencies and improve the relevancy of science to decision makers. The model should be spatially explicit to quantify the change in diverse ecosystem services expected from proposed changes in land use and/or under changing climate projections. For example, it would be possible to identify potential land use strategies to maintain the current or some desired level of net ecosystem exchange of $\mathrm{CO}_{2}$ under a changing global climate while simulta- neously quantifying the impact on diverse ecosystem services; this would provide decision makers with a comprehensive view of ecosystem response to avoid unintended, and potentially negative, consequences of land use management. Further, model outputs should calculate the uncertainty associated with estimates of specific ecosystem services to provide a transparent means for users to identify information to improve model forecasts. Decision makers could then more effectively communicate critical information needs to scientists. Finally, because the overall modeling strategy would be linked to ongoing monitoring data, model output from discrete time frames would satisfy reporting requirements to the Office of Management and Budget and would facilitate adaptive management and policy goals of specific agencies.

\section{Data-assimilation modeling}

Frame-based models need to be sufficiently complex to simultaneously quantify impacts of land use and climate change on a full range of ecosystem services. This will provide the holistic perspective needed by decision makers to consider trade-offs resulting from various actions. Development and adaptation of datamodel fusion or data assimilation techniques (Canadell et al. 2004, Raupach et al. 2005) is a proven method that provides the necessary linkage to refine model estimates through an adaptive process between previous model projections and changing monitoring signals (Fig. 2). The ultimate goal is development of an integrated data assimilation system that estimates key ecosystem services based on metrics at spatial scales of $\sim 30 \mathrm{~m}$ to $250 \mathrm{~m}$ (98 to 820 feet), which will allow use of geographical information systems databases.

Data assimilation techniques are available to improve monitoring and forecasting capability by dynamically incorporating continuous observations (Kalnay 2003, Raupach et al. 2005) into an adaptive model refinement process. Assimilation into an integrated ecosystem service model of near-real-time ecosystem states and processes may also reduce scaling errors associated with traditional modeling because explicit estimates of temporal and spatial covariance in ecosystem processes and services can be constrained by many simultaneous observations (Ping and Barrett 2003). To our knowledge, no data-model fusion systems exist for simultaneously quantifying a full spectrum of diverse ecosystem services in wetlands. To develop such a data-model fusion system, we need integrated interdisciplinary ecosystem service models, field and remote-sensing observations, and data-model fusion schemes. These components will be discussed briefly in the following paragraphs.

The process of developing integrated, interdisciplinary ecosystem service models begins with traditional discipline-specific models that usually quantify a narrow set of ecosystem services. For example, traditional wildlife habitat models (e.g., Guisan and Zimmermann 2000) 
usually do not simulate dynamics of carbon and nitrogen in vegetation and soil (e.g., Liu et al. 2003). Identifying, integrating, and modifying these traditional models will require coordinated collaborative efforts among a wide range of disciplinary experts. Efforts for quantifying major ecosystem services can be carried out simultaneously (i.e., concurrent model development for specific ecosystem services) by different teams collaborating at different geographic locations. However, an alternative additive approach (i.e., disciplinary models are iteratively added during the course of model development) can also be applied when a simultaneous full deployment is prohibited by availability of resources.

Observations and their errors are another key component for developing a data-model fusion system. Many spatial base data layers (e.g., soils, vegetation, geology, digital elevation models) exist for the study regions. Dynamic changes of many ecosystem states, processes, and services also have been observed and monitored using various networks. One major challenge, however, is deriving distributional information for the errors associated with various observations. Errors in data sets greatly affect data assimilation (Kalnay 2003, Raupach et al. 2005) because the constraining strengths of data sets on model simulations are inversely proportional to the magnitudes of their corresponding errors. Data sets with lower uncertainties will thus constrain model simulations more than those with higher uncertainties. There is a need also to investigate impacts of random versus systematic errors and how changes in error structure affect quantification of ecosystem services. Results generated from such exercises can be very useful for optimizing observation networks to improve monitoring and forecasting accuracy.

The last component of data fusion models is the development of a data assimilation scheme. Many assimilation methods have been developed and can be grouped into sequential and nonsequential methods (Kalnay 2003, Raupach et al. 2005). In sequential methods, data arrive in the data-model fusion system in time sequence and are assimilated stepwise as the system moves forward in time, whereas in nonsequential methods, all data arrive and are incorporated at the same time. Sequential methods may offer advantages over nonsequential methods in some applications. For example, sequential methods generally provide more dynamic quantification of ecosystem services by accommodating time-dependent observations without any increase in computational effort. Among sequential data assimilation methods, the ensemble Kalman filter has been widely used in applications owing to its success in dealing with strongly nonlinear systems and its capability of significantly reducing the computational burden of measurement updating (Evensen 1994, 2003).

\section{Monitoring integration}

Although data-model fusion systems go beyond conventional monitoring approaches (e.g., survey and remote sensing), the systems still rely on conventional monitoring networks. Nevertheless, data-model fusion systems can be used to improve the deployment of monitoring networks and identify the key elements that need to be monitored to meet certain reporting requirements, improve monitoring networks, and identify relations between ecosystem responses to change. In many of our projects, future data collection will be based largely on remote-sensing technology to (1) reduce operating costs, (2) provide data across the entire regional landscape, and (3) provide near-real-time flow of data into the data-model fusion systems to facilitate near-real-time simultaneous monitoring and forecasting of ecosystem services over time and space.

Data layers derived from remote-sensing technology need to be carefully ground-truthed and uncertainties assessed to improve model estimates, strengthen remotesensing mapping techniques, and improve the relevancy of applied research to agency objectives. The CEAPWetlands investigations that are underway provide basic data and the understanding to develop ecosystem service models, validate remotely sensed data, and evaluate sample size requirements to detect significant change. Remote-sensing techniques have successfully been used to map the dynamics of surface water in wetlands in the Prairie Pothole Region and to predict hydrologic and geochemical functions (e.g., discharge, recharge, and flow-through). These data layers can be valuable for the development and testing of the frame-based wetland model at the landscape to regional scales.

\section{Role of Ecological Setting on the Drivers of ECOSYSTEM FunCTION}

The global diversity of ecosystems reflects unique formation events where depositional or erosional (e.g., glaciers), structural (e.g., volcanoes), or weathering (e.g., Karst topography) processes defined their functional attributes (Euliss and Laubhan 2005). Even in landscapes highly modified by man, characteristics derived from formation processes, in concert with climate, are forces that set limits on services provided by all ecosystems. Thus, outcomes produced from conservation practices and programs depend upon how their design and implementation is integrated with the natural processes of unique ecosystems (Euliss and Laubhan 2005). We define the basic natural drivers of ecosystem function in four geographic areas where CEAPWetlands investigations are being conducted and outline a conceptual process for integrating them into a dynamic ecosystem process model to enhance adaptive monitoring, management, and policy evaluation.

\section{The Prairie Pothole Region}

In the Prairie Pothole Region, a glacial topography interacts with climate to provide a diversity of ecosystem services (Gleason et al. 2008). Key factors affecting these services are mineral-rich soils and a highly dynamic interannual climate cycle that produces infrequent wet 
periods interspersed with prolonged drought (Euliss et al. 1999). While the interannual climate drives ecosystem processes that maintain a diverse biota (Euliss et al. 2004), impacts on agricultural crops are often negative, resulting in boom-or-bust commodity production.

Wetlands comprise $\sim 17 \%$ of the land area in the Prairie Pothole Region (Euliss et al. 2006), and are the foci of ecosystem services that include carbon sequestration for climate stability, groundwater recharge, nutrient retention, runoff and flood attenuation, water storage, contaminants filtering, and wildlife habitat. Hence, base models to forecast change in ecosystem services in the Prairie Pothole Region must integrate wetland processes into data assimilation systems. Because different wetlands in the Prairie Pothole Region temporally shift among specific vegetative phases (Stewart and Kantrud 1971) in relation to interannual climate cycles, wetland phases are well suited for modeling as ecosystem frames (Starfield et al. 1993) corresponding with each functional type of wetland (see review in Euliss et al. 2004). Hydrology (e.g., pool depth, hydroperiod) and geochemical attributes (e.g., solute chemistry, specific conductance) are related to natural driving factors (i.e., wetland hydrologic function and interannual climate variability) that define specific abiotic conditions of wetlands and therefore constrain the expression of specific ecosystem services. Recently, we developed a distributed geospatial model that simulates water dynamics to forecast myriad ecosystem services of wetlands in the Prairie Pothole Region (Feng et al. 2009). This is a model-sharing platform based on interoperability standards that can easily be expanded to include other geographic areas, including the other CEAP-Wetlands regional assessment areas.

The wetland continuum model developed by Euliss et al. (2004) provides a conceptual basis for the framebased model because temporal change in hydrogeochemical conditions in wetlands can be related to specific vegetative phases for each hydrologic functional wetland type (e.g., recharge, flow-through, and discharge) in the Prairie Pothole Region. The wetland continuum model consists of several frames that constitute a set of related abiotic and biotic conditions that are intrinsically linked with the performance and transitions of all other frames identified in the continuum. Ecosystem services derived from wetlands can thus be quantitatively estimated from the specific abiotic conditions within individual frames, representing different combinations of hydrology, chemistry, and geomorphology. Because frame transitions are visually unique (i.e., they correspond with temporal phase changes in wetland vegetation), integrating nearreal-time monitoring data from satellite sensors offers a means to develop an adaptive modeling procedure to refine forecasts over time.

\section{Playa wetlands of the High Plains}

The basic model described for the Prairie Pothole Region can be easily applied to the High Plains, where most playa wetlands occur (Smith 2003). Playas are shallow depressional recharge wetlands each existing within their own watershed. The hydrology of playas is simpler (Luo et al. 1997) than that of potholes and therefore would require fewer model frames. Primary services provided by playas include habitat for biodiversity, floodwater storage, groundwater recharge, and contaminant filtration. As an example, with data from ongoing studies of the effects of conservation practices on groundwater recharge, a decision maker could enter one or more specific conservation practices (e.g., conservation cover) into the model to estimate the potential amount of water that could be recharged over a landscape. The model output would provide an objective means of making conservation practice decisions regarding the ecosystem services provided by groundwater recharge.

\section{Wetlands in the Central Valley of California}

Wetlands in the Central Valley of California are primarily freshwater marshes with either seasonal or semipermanent hydrologic regimes, riparian wetlands, or vernal pools. Today, $>90 \%$ of these wetlands are managed, and two-thirds of managed wetlands are in private ownership (Central Valley Joint Venture 2006). Hydrology in these wetlands ranges from being somewhat simple in vernal pools to complex in riparian wetlands and highly artificial in restored freshwater marshes. Despite this variability, ecosystem services provided by Central Valley wetlands are similar with those associated with wetlands in the Prairie Pothole Region or High Plains and include biodiversity, floodwater storage, groundwater recharge, and nutrient and contaminant filtration. The proposed model could guide decision makers in California, where precipitation is temporally variable and limits human activities. One application could be to model potential water storage capacity in restored wetlands while simultaneously forecasting benefits in groundwater recharge, biodiversity, water quality improvements, and carbon sequestration.

\section{Lower Mississippi Valley wetlands}

Historically, the Lower Mississippi Valley was dominated by floodplain forests and wetlands intimately connected to the Mississippi River and its tributaries (MacDonald et al. 1979). In this native state, wetlands were sinks for sediments and nutrients, provided temporary storage of floodwaters, stored significant amounts of carbon in tree biomass and soils, and provided extensive habitat for flora and fauna. At a broad scale, hydrology is the primary driver of wetland ecosystem services in the Lower Mississippi Valley. The natural flood-pulse cycle (Junk et al. 1989) of seasonal (winter and spring) flooding and ponding of surface runoff provides water, sediments, and nutrients, all of which determine plant community composition and hydrologic and biogeochemical functions (Faulkner 2004). 
Much of the Lower Mississippi Valley landscape has been altered by river channelization, artificial drainage, flood control levees, and land use change. More than $75 \%$ of the original riparian forest has been converted to other land uses, primarily row crop agriculture, with highly fragmented patches remaining (Twedt and Loesch 1999). This landscape-scale disturbance has changed the natural flood-pulse cycle, resulting in the loss of important ecosystem services.

The frame-based modeling approach will be used in the Lower Mississippi Valley to quantify ecosystem services derived from landscapes comprised of different land uses. Each frame will represent a landscape with a specific amount and spatial arrangement of active cropland, natural forests, and restored forests at a point in time. Model runs can quantify changes in the suite of ecosystem services resulting from aging of the forest ecosystem; technical improvements in restoration/conservation practices; economic, policy, or management decisions affecting the amount of active cropland or conservation practices on the landscape; or some combination of these conditions. This type of modeling allows managers, landowners, stakeholders, and policy makers to evaluate the ecological trade-offs involved in choosing among various alternatives in complex landscapes.

\section{Conclusions}

Conservation in the United States is a relatively new field that began in the early part of the past century, largely in response to widespread conversion of native landscapes to accommodate a growing human population. Concurrent with this conversion and the human population explosion, our demand for ecosystem services has increased over fivefold (e.g., Karlin 1995). Careful management of ecosystems within our modern and highly modified landscape holds the future for the intergenerational sustainability of ecosystems. Requisite to such management is an understanding of how land use affects delivery of multiple and simultaneous ecosystem services within the context of processes that regulate ecosystem function. Development of costeffective, integrated, and adaptive modeling of ecosystem services using assimilation approaches that take advantage of monitoring systems and ever-improving data such as those supported by efforts like CEAPWetlands can be used to facilitate ecosystem management at the landscape scale.

\section{ACKNOWLEDGMENTS}

We thank D. M. Mushet, J. A. Rover, and C. K. Wright for commenting on a draft of this article, and K. E. Kermes for preparing the figure.

\section{Literature Cited}

Canadell, J. G., P. Ciais, P. Cox, and M. Heimann. 2004. Quantifying, understanding and managing the carbon cycle in the next decades. Climatic Change 67:147-160.

Central Valley Joint Venture. 2006. Central Valley Joint Venture Implementation Plan: conserving bird habitat. U.S. Fish and Wildlife Service, Sacramento, California, USA.
Christensen, N. L., et al. 1996. The report of the Ecological Society of America Committee on the scientific basis for ecosystem management. Ecological Applications 6:665-691.

Daily, G. C., editor. 1997. Nature's services: societal dependence on natural ecosystems. Island Press, Washington, D.C., USA.

Euliss, N. H., Jr., R. A. Gleason, A. Olness, R. L. McDougal, H. R. Murkin, R. D. Robarts, R. A. Bourbonniere, and B. G. Warner. 2006. North American prairie wetlands are important nonforested land-based carbon storage sites. Science of the Total Environment 361:179-188.

Euliss, N. H., Jr., J. W. LaBaugh, L. H. Fredrickson, D. M. Mushet, M. K. Laubhan, G. A. Swanson, T. C. Winter, D. O. Rosenberry, and R. D. Nelson. 2004. The wetland continuum: a conceptual framework for interpreting biological studies. Wetlands 24:448-458.

Euliss, N. H., Jr., and M. K. Laubhan. 2005. Quantifying the environmental benefits of the Conservation Reserve Program on prairie wetlands: separating acts of nature from acts of Congress. Pages 11-15 in A. W. Allen and M. W. Vandever, editors. The Conservation Reserve Program-planting for the future: proceedings of a national conference, Fort Collins, Colorado, USA, 6-9 June, 2004. Special Investigations Report 2005-5145. U.S. Geological Survey, Reston, Virginia, USA.

Euliss, N. H., Jr., D. A. Wrubleski, and D. M. Mushet. 1999. Invertebrates in wetlands of the Prairie Pothole Region: species composition, ecology and management. Pages 471514 in D. Batzer, R. B. Rader, and S. A. Wissinger, editors. Invertebrates in freshwater wetlands of North America: ecology and management. John Wiley and Sons, New York, New York, USA.

Evensen, G. 1994. Sequential data assimilation with a nonlinear quasi-geostrophic model using Monte Carlo methods to forecast error statistics. Journal Geophysical Research 99: 10143-10162.

Evensen, G. 2003. The ensemble Kalman filter: theoretical formulation and practical implementation. Ocean Dynamics 53:343-367.

Faulkner, S. P. 2004. Soils and sediment: understanding wetland biogeochemistry. Pages 30-54 in S. L. Spray and K. L. McGothlin, editors. Wetlands. Rowman and Littlefield, Landam, Maryland, USA.

Feng, M., S. Liu, N. H. Euliss, Jr., and F. Yin. 2009. Distributed geospatial model sharing based on open interoperability standards. Journal of Remote Sensing 13:1060 1066.

Gleason, R. A., M. K. Laubhan, and N. H. Euliss, Jr., editors. 2008. Ecosystem services derived from wetland conservation practices in the United States Prairie Pothole Region with emphasis on USDA Conservation Reserve and Wetland Reserve Programs. U.S. Geological Survey, Professional Paper 1745. USGS, Reston, Virginia, USA.

Guisan, A., and N. E. Zimmermann. 2000. Predictive habitat distribution models in ecology. Ecological Modeling 135: 147-186.

Junk, W. J., P. B. Bayley, and R. E. Sparks. 1989. The floodpulse concept in river-floodplain systems. Canadian Special Publication of Fisheries and Aquatic Sciences 106:110-127.

Kalnay, E. 2003. Atmospheric modeling, data assimilation and predictability. Cambridge University Press, Cambridge, UK. Karlin, E. F. 1995. Population growth and the global environment: an ecological perspective. Pages 19-37 in W. J. Makofske and E. F. Karlin, editors. Technology, development and global environmental issues. Harper Collins, New York, New York, USA.

Liu, S., N. Bliss, E. Sundquist, and T. Huntington. 2003. Modeling carbon dynamics in vegetation and soil under the impact of soil erosion and deposition. Global Biogeochemical Cycles 17:1074. 
Luo, H. R., L. M. Smith, B. L. Allen, and D. A. Haukos. 1997. Effects of sedimentation on playa wetland volume. Ecological Applications 7:247-252.

MacDonald, P. O., W. E. Frayer, and J. K. Clauser. 1979. Documentation, chronology and future projections of bottomland hardwood habitat losses in the Lower Mississippi Alluvial Plain. U.S. Department of the Interior, U.S. Fish and Wildlife Service, Washington, D.C., USA.

Ping, W., and D. J. Barrett. 2003. Estimating regional terrestrial carbon fluxes for the Australian continent using a multipleconstraint approach. I. Using remotely sensed data and ecological observations of net primary production. Tellus B 55:270-289.

Raupach, M. R., P. J. Raynerw, D. J. Barrett, R. S. DeFries, M. Heimann, D. S. Ojima, S. Quegan, and C. C. Schmullius. 2005. Model-data synthesis in terrestrial carbon observation: methods, data requirements and data uncertainty specifications. Global Change Biology 11:378-397.

Smith, L. M. 2003. Playas of the Great Plains. University of Texas Press, Austin, Texas, USA.

Starfield, A. M., D. H. M. Cummings, R. D. Taylor, and M. S. Quadling. 1993. A frame-based paradigm for dynamic ecosystem models. Artificial Intelligence Applications 7:1-13. Stewart, R. E., and H. A. Kantrud. 1971. Classification of natural ponds and lakes in the Glaciated Prairie Region. Resource Publication 92. Bureau of Sport Fisheries and Wildlife, Washington, D.C., USA.

Twedt, D. J., and C. R. Loesch. 1999. Forest area and distribution in the Mississippi Alluvial Valley: implications for breeding bird conservation. Journal of Biogeography 26: $1215-1224$. 